Archives de sciences sociales des religions

176 | octobre-décembre 2016

Bulletin Bibliographique

\title{
Le débat sur le catholicisme populaire en France (1960-1980)
}

Une crise de légitimité

André Rousseau

\section{OpenEdition}

\section{Journals}

Édition électronique

URL : http://journals.openedition.org/assr/28122

DOI : $10.4000 /$ assr.28122

ISSN : $1777-5825$

Éditeur

Éditions de l'EHESS

Édition imprimée

Date de publication : 31 décembre 2016

Pagination : 137-152

ISSN : 0335-5985

Référence électronique

André Rousseau, «Le débat sur le catholicisme populaire en France (1960-1980) », Archives de sciences sociales des religions [En ligne], 176 | octobre-décembre 2016, mis en ligne le 01 janvier 2019, consulté le 04 janvier 2020. URL : http://journals.openedition.org/assr/28122 ; DOI : 10.4000/assr. 28122

(c) Archives de sciences sociales des religions 


\section{André Rousseau}

\section{Le débat sur le catholicisme populaire en France (1960-1980)}

\section{Une crise de légitimité}

Dans les années 1970, en Amérique latine, en Europe francophone et au Québec, la sociologie a été prise dans un débat à triple entrée sur la « religion populaire ". Elle a pu d'abord être invoquée comme argument face aux historiens et aux clercs. Des sociologues ont ensuite inscrit la question dans les effets divers du concile Vatican II, ainsi que dans les théories de la sécularisation, puisque l'une des acceptions du terme religion "populaire " renvoie à ce qu'il y a d'archaïque ou peu rationalisé, dans les attitudes religieuses. Enfin ce débat soulevait la question de la différenciation des comportements religieux selon les classes sociales et ipso facto, celle des effets de ce phénomène sur la dynamique interne au monde catholique.

On n'a peut-être pas suffisamment prêté attention à certains éléments de la chronologie des publications. Ce qui attire la mienne en tout cas est peut-être idiosyncrasique, et tient à la contribution écrite que j'ai apportée au débat. Si l'on prend comme point de départ le travail de Serge Bonnet sur Saint Rouin (1956), on pourrait remarquer que le dernier numéro de Jeunesse de l'Église est de 1955, dont la préoccupation missionnaire identifie le "peuple " chrétien à la classe ouvrière et celle-ci au Parti communiste. En 1963, la revue Parole et Mission titre : "Les sacrements livrés à l'incroyance ", tandis que Bonnet ferraille avec le clergé, dès 1969, sur la volonté de supprimer la communion solennelle et sur le catholicisme populaire jusqu'en 1977. Mais cette année-là, il le fait dans le cadre d'un colloque organisé par le CNRS sur le sujet, tandis que FrançoisAndré Isambert avait posé un premier diagnostic sociologique sur la question et ses protagonistes en $1975^{1}$, et y revient de façon plus ample en 1982.

En regard de cette chronologie volontairement sommaire, il est intéressant de noter que la sociologie est mêlée à un débat bien plus global, mais qui n'est

1. F.-A. Isambert, "Autour du catholicisme populaire. Réflexions sur un débat ", Social Compass, XXII, 1975/2, 193-210; Id., Le sens du sacré. Fête et religion populaire, Paris, Éditions de Minuit, 1982. 
pas sans relation avec celui qui nous occupe : dès 1964, en élucidant dans Les Héritiers le rôle de l'école et plus largement de la culture consacrée, Pierre Bourdieu et Jean-Claude Passeron lancent une interrogation sur le rôle de la maîtrise de la culture "légitime ", dans les rapports de domination entre les classes sociales $^{2}$. Deux années plus tard, L'amour de l'art ${ }^{3}$, mais aussi Le Partage des Bénéfices ${ }^{4}$ ancrent l'idée que les différences de maîtrise de la culture consacrée sont un déplacement des inégalités économiques dans le domaine des consommations symboliques. Cette idée est puissamment mise en œuvre dans La Distinction en $1979^{5}$, et Passeron, en compagnie de Claude Grignon, en discutera la pertinence ou les inconvénients, dans un séminaire tenu en 1982 et dont les travaux sont publiés en $1989^{6}$.

Résumons les enjeux et les concepts mis en œuvre dans ce débat sociologique, avant d'en voir les similitudes avec les questions débattues entre catholiques. Cette sociologie braque le projecteur sur les dimensions culturelles, immatérielles ou symboliques de la vie sociale, au motif que sous cette forme, les rapports sociaux n'y apparaissent pas comme des relations de force, comme il en va dans l'univers économique. Goûts et connaissances culturelles apparaissent comme des propriétés des personnes et modifiables par une éducation. Or celle-ci, dans ses tentatives de cultiver ou " élever » le peuple, se heurte à l'apprentissage par familiarité qui est le propre des classes supérieures qui sont aussi les classes «cultivées ". Bourdieu et Passeron empruntent à Max Weber le concept de «culture légitime ". Ils désignent sous ce terme celle qui s’impose comme loi ou norme universelle et dont le caractère arbitraire - au sens de l'arbitraire du signe échappe à tout le monde, tout en apportant à ceux qui en ont la maîtrise et aussi la créent, des profits symboliques descriptibles selon le principe : le capital va au capital... Le phénomène est observable sous la forme de titres scolaires qui permettent d'entrer et d'évoluer dans les classes supérieures ou la « noblesse d'état ", et qui fonctionnent à la manière des atouts dont on dispose dans un jeu, mais qui sont aussi des mécanismes de sélection, en vertu du principe énoncé. Et Bourdieu va au bout de cette logique «culturelle » en proposant quasiment dans La Distinction une description et une théorie des classes sociales à partir de l'analyse des goûts culturels.

C'est ici qu'il est possible de rattacher les deux débats : sociologique et " pastoral ». Deux concepts majeurs de La Distinction vont le permettre. D'abord

2. P. Bourdieu, J.-C. Passeron, Les héritiers, Paris, Éditions de Minuit, 1964.

3. P. Bourdieu, A. Darbel, L'amour de l'art. Les musées d'art européens et leur public, Paris, Éditions de Minuit, 1966.

4. Bourdieu est l'un des inspirateurs principaux de cette réflexion entre sociologues et économistes publiée sous la signature pseudonyme Darras, Éditions de Minuit, 1966.

5. P. Bourdieu, La distinction. Critique sociale du jugement, Paris, Éditions de Minuit, 1979.

6. C. Grignon, J.-C. Passeron, Le savant et le populaire. Misérabilisme et populisme en sociologie et en littérature, Paris, EHESS/Gallimard, 1989. 
celui d'homologie puis celui de transférabilité. L'idée d'homologie ${ }^{7}$ qui exprime les similitudes observables entre deux champs est ici particulièrement intéressante, en ce que Bourdieu - dans sa théorie des champs - insistait sur le fait qu'il n'est pas nécessaire qu'il y ait interaction visible pour qu'il y ait une relation objective. Entre le débat sur le catholicisme populaire et celui sur la culture légitime, il y a un point commun qui est l'école, ou plus exactement les effets qu'elle entraîne dans le rapport des individus aux savoirs et aux "régimes de vérité ${ }^{8}$, mais aussi dans le double effet qu'elle produit. Elle élargit l'accès à la culture au point que l'espace social est aussi structuré par la distribution du capital culturel $^{9}$, mais elle le fait dans les limites d'une translation des positions de pouvoir. Bien évidemment, les questions inédites et les tensions qui en résultent ne prennent pas la même forme; et pourtant sous la formule « religion populaire » s'expriment des questions dont l'origine la plus manifeste est clairement le Concile, mais qu'il faut réinsérer, pour parler concrètement de la France des années 70, dans la modification de l'origine sociale du clergé, dans les capacités des classes moyennes scolarisées à peser sur la définition des normes religieuses, mais aussi dans les réactions des détenteurs d'un capital religieux désigné, du coup, comme obsolète. Celles-ci peuvent choisir le retrait pour les moins scolarisés, ou, à l'inverse, tenter la reconquête pour la bourgeoisie traditionnelle ${ }^{10}$. Enfin plus globalement, le débat sur la religion populaire, et l'on pourrait dire la même chose de la culture populaire en général, illustre les difficultés inédites rencontrées par l'ajustement entre l'offre culturelle et la demande, et soulevées en conséquence pour les producteurs. Pour formuler le problème dans des termes célèbres : faut-il éduquer le peuple ou changer de peuple ? Quant à la transférabilité, disons simplement que ce concept désigne le fait vérifiable, même s'il connaît des exceptions, que les goûts des individus ont un fort degré d'homogénéité dans les divers domaines où ils s'expriment. Le problème des " producteurs " de biens symboliques revient, dans une société où la norme culturelle est objet de débat, à adapter leur discours à des demandes peu compatibles avec ce qu'ils offrent.

7. Cette idée venue de la «perspective » en peinture, passée par les sciences de la nature, mais aussi la linguistique, devient une clé de voûte du structuralisme. L. Goldman l'emploie en sociologie de la littérature. Et sur ce plan Bourdieu procède à une révision profonde du modèle. Cf. O. Roueff, "Les homologies structurales : une magie sociale sans magicien ? ", in Coulangeau P., Duval J. (dir.), Trente ans après. La distinction de Pierre Bourdieu, Paris, Éditions La Découverte, 2013, p. 153-164.

8. Le terme est de M. Foucault et il est emprunté par J. Lagroye dans une théorie du fonctionnement institutionnel du catholicisme que j'évoquerai plus loin.

9. En ce sens, La Distinction est un tableau de la société française.

10. La «manif pour tous » est un prolongement de ce processus, mais elle manifeste aussi une gentrification sensible du groupe catholique, la substitution d'une bourgeoisie " moderne " à une bourgeoisie "de tradition ". Voir sur ce point G. Cuchet, "L'entrée des catholiques dans l'ère communautaire ", Esprit, no 397, août-septembre 2013, p. 200. 


\section{Les armes de la critique : échos d'un débat}

Parmi les résolutions du Concile Vatican II qui ont eu un effet direct sur la question de la religion populaire, on peut mentionner le fait qu'une Église « en quête de liberté » ${ }^{11}$ ou du moins une partie des catholiques cultivés et du clergé, a pu passer à l'acte, en quelque sorte, et entreprendre de renouveler simultanément - en toute logique - la lex credendi et la lex orandi. La valorisation du laïcat, ou de "l'autonomie des réalités terrestres ", légitimait une vision renouvelée des rites, dans laquelle l'implication personnelle et la prise en compte de toutes les dimensions de la vie sociale étaient élevées au rang de prérequis. La participation à la messe devient centrale et sa pratique, qui était depuis longtemps un indice et même une mesure de l'appartenance à l'Église ${ }^{12}$, contribua à dévaloriser d'autres rites, à les faire voir sinon comme un reste, du moins comme un complément de l'essentiel, dans une hiérarchie des pratiques. On se mit à discuter sur le point de savoir si ces pratiques subalternes renvoyaient à ce que Gabriel Le Bras nommait un « conformisme saisonnier ». Il s'agissait des rites déroulant un cycle de vie, du baptême à la communion solennelle, aux funérailles en passant par le mariage et le baptême des enfants. Ces rites doivent-ils être valorisés comme appartenant à " un catholicisme festif » ainsi que le proposera Bonnet, non seulement pour gommer le caractère «oblique » du rapport à la religion impliqué dans ces " habitudes » ou ces «traditions ", mais surtout pour lui donner un contenu positif.

La conjoncture entrelace alors au moins trois dimensions conflictuelles. En premier lieu des tensions entre clercs, structurées à la fois par des phénomènes de générations, et par les conflits qui, au moins en France, opposent la "paroisse » et le culte, à la "mission "; l'Action Catholique, notamment ouvrière, étant dans ce contexte, un compromis penchant fortement du côté de la mission ${ }^{13}$.

11. Je fais référence au livre d'É. Fouilloux, Une Église en quête de liberté. La Pensée catholique française entre modernisme et Vatican II, 1914-1962. On y trouve un tableau précis des aspirations du clergé et des militants catholiques qui, étant arrivés à l'âge adulte dans les années conciliaires, purent imprimer leur marque dans la pastorale des années 70. J.-M. Mayeur décrit cette mise en question de la "pastorale des sacrements ", qui affleure dès 1963, avec un numéro de la revue Parole et Mission, du 4 décembre 1963, intitulé «Les sacrements livrés à l'incroyance ». Cf. J.-M. Mayeur, «Des clercs devant la religion populaire : aux origines d'un débat ", in La religion populaire. Colloque des 17-19 octobre 1977, Paris, Éditions du CNRS, 1980, p. 339-346.

12. D. Hervieu-Léger fait remarquer que les enquêtes de pratique dominicale avaient laissé aux folkloristes l'observation des dévotions, des pèlerinages et du culte des saints guérisseurs; cf. D. Hervieu-Léger, Vers un nouveau christianisme, Éditions du Cerf, 1986, p. 109. Il faut rappeler ici que $S$. Bonnet avait précédé la vague de la religion populaire avec son étude sur Saint Rouin, dès 1956, rééditée par les soins de Y. Raison du Cleuziou dans l'introduction qu'il donne à S. Bonnet, Défense du catholicisme populaire, Paris, Éditions du Cerf, 2015, p. 51-208.

13. Pour illustrer les présupposés de ce contexte, je peux mentionner que des témoins crédibles m'ont rapporté, dans une paroisse de la banlieue nord de Paris, qu'un dimanche matin, vers la fin des années 50 , les paroissiens trouvèrent portes closes et cette affiche expliquant: "fermé pour cause de mission ». 
En second lieu, au nom du sacerdoce des baptisés, un partage paradoxal s'instaure, pour une partie du clergé, entre les «laïcs engagés " dans la société et les autres ; l'expression "clergé socio-culturel» de Bonnet exprime et dénonce ce partage, et veut faire voir dans la défense du catholicisme populaire une saine réaction contre cette prise de pouvoir abusive. Enfin, le terme "populaire " se trouva pris en conséquence, entre une acception sociologique, voire médiatique, et une autre franchement politique : la méfiance envers le catholicisme populaire est la conséquence d'une valorisation du "catholique militant ", par un clergé qui préfère la classe au "peuple » et épouse implicitement, dans sa vision de la culture, une théorie sociologique de la conscience de classe.

\section{Les protagonistes}

Comment les protagonistes du débat des années 1970 argumentent-ils ? Mais d'abord, qui sont les protagonistes ? François Isambert en identifie trois, dont aucun n'est parfaitement homogène : le clergé, "les clients », fidèles plus ou moins organisés, et les interprètes, sociologues, historiens, ethnologues. Serge Bonnet se situe à l'intersection des trois ensembles, il est religieux dominicain, il est sociologue et comme religieux et sociologue, il connaît avec précision le " peuple» dont il se fait l'avocat.

Jean-Marie Mayeur schématise en trois traits le débat ouvert parmi les clercs et les théologiens de profession dans les années $1960^{14}$. Tout d'abord, l'enjeu n'est pas nommé « religion populaire », mais porte sur les préalables nécessaires à une réception des sacrements : compte tenu de ce que l'on sait sur l'abandon de la pratique, et la faiblesse de connaissances religieuses, faut-il continuer à " livrer les sacrements à l'incroyance " ? Deuxième trait : les travaux des sociologues sont instrumentalisés à des fins doctrinales. Certains voient dans ces analyses sociologiques l'indice d'une demande encore soutenue des pratiquants "saisonniers " et veulent modifier en conséquence les méthodes de la catéchèse. D'autres, faisant remarquer que la participation aux organisations catholiques est nettement plus faible que la demande de rites, veulent revaloriser « l'engagement militant » profane, car ils sont certains que la chrétienté a disparu. Enfin, le débat porte - et ce n'est pas une nouveauté historique - sur ce que doit être l’Église : une élite ou une masse ? L'administration du sacré (religion) ou une communauté de conviction (la foi)?

Du côté des fidèles on peut, pour simplifier, distinguer, d'une part des groupes organisés, militants ou " groupes de pression ", et de l'autre, les individus demandeurs de rites. Chez les premiers on retrouve les catholiques cultivés ou militants que j'ai évoqués plus haut, alliés à un clergé qui veut remettre en cause la gestion ordinaire de la demande. En face d'eux s'organisent en une nébuleuse parfois

14. J.-M. Mayeur, article cité, p. 346. 
nommée "les silencieux ", des catholiques refusant qu'on leur change la religion (dont le latin) et qui vont devenir de plus en plus pugnaces, avec par exemple l'occupation de l'église Saint Nicolas du Chardonnet à Paris, mais bien sûr autour de Mgr Marcel Lefebvre et de sa Fraternité Saint Pie X. Entre les deux la grande masse des "pratiquants saisonniers " : ils n'en pensent rien ou pas grand-chose, et pas grand-chose non plus ne les relie à l'organisation ecclésiale, même s'ils se disent catholiques. Ils ne comprennent pas qu'on bouleverse les rites, qu'on pose des préalables à l'obtention du baptême, d'une cérémonie de mariage... L'incompréhension parfois manifestée à haute voix a dû souvent favoriser des « exit ", pour reprendre le modèle d'Albert Hirschman ${ }^{15}$, là où le clergé se montrait peu accommodant ; mais il n'est pas nécessaire de comprendre pour respecter une autorité légitime, ou au moins "faire avec ». Là se greffe le débat avec les sociologues.

\section{Les prises de position de Serge Bonnet}

Les interventions vigoureuses de Bonnet à propos de la « religion populaire » expriment un " tempérament ", mais aussi une position dans les conflits internes aux catholiques. Il faut rappeler que ces interventions avaient une dimension proprement sociologique. Je pense à l'article séminal de 1971 intitulé : "Une hypothèse de recherche : le clergé et la petite bourgeoisie en France » ${ }^{16}$. Il y avançait que le clergé de l'époque, surtout sa jeune génération, tendait à adopter une attitude malthusienne dans l'administration des sacrements. La recherche d'une cohérence meilleure entre pratique des rites et convictions, voire la connaissance du dogme et de ses conséquences pratiques, effectue objectivement une sélection qui décourage les classes populaires. Bonnet rattache ce comportement du clergé à son caractère petit-bourgeois qui prend ses distances avec le peuple tout en prétendant œuvrer pour son émancipation.

Bonnet pensait relationnellement, dans un univers où pasteurs et même historiens idéalisaient des contenus ou des « essences " de la « religion populaire ». En témoignent ses propres prises de position, tout comme la mise en évidence des motivations ou des mobiles des autres acteurs; le recueil de ses écrits en donne de nombreux exemples ${ }^{17}$. Il s'agissait pour lui de comprendre comment - au moins en partie - la religion populaire est " produite » quand l'élite éclairée la met à distance ou la réprouve.

15. Cf. A. O. Hirschman, Exit, voice and loyalty, Harvard University Press, Cambridge Massachusetts, 1970 (tr. fr. par Claude Besseyrias, Exit, voice, loyalty. Défection et prise de parole, Bruxelles, Éditions de l'Université de Bruxelles, 2011).

16. Centre Catholique des Intellectuels Français, Élites et masses dans l'Église, Paris, Desclée de Brouwer, 1971, p. 133-144.

17. S. Bonnet, op. cit. 
Cela minimisait le risque pris, voire assumé et contrôlé par Bonnet, d'adopter une attitude populiste, prenant le contrepied de jugements du « clergé socioculturel ». Dans sa polémique avec ce clergé, il met au jour les raisons des positions qu'il critique en s'attachant à faire une sociologie des origines et de l'organisation du clergé ${ }^{18}$. D'origine de plus en plus urbaine, en affinité avec les classes moyennes cultivées, ce clergé parle d'autant plus du peuple qu'il s'en éloigne, dit-il de multiples fois et de multiples manières. C'est ainsi qu'il interprète les réticences du clergé vis-à-vis de la tradition des communions solennelles, comme une façon de revaloriser son statut, de ne pas être ravalé au rang d'organisateur de fêtes collectives. Dans une image qui condense un jugement sur la société de consommation et le refus d'être assimilé à un métier d'employé de "service ", donc en défense d'un statut libéral, l'un des auteurs de France, pays de mission, Yvan Daniel, n'écrivait-il pas en 1973 : «Les prêtres ne veulent plus travailler dans un supermarché religieux " ${ }^{19}$ ? Réponse du berger à la bergère, Bonnet nomme ceci le «malthusianisme baptismal », qui consiste à relever la barre des exigences religieuses imposées aux parents qui demandent le baptême pour un enfant. Et de conclure: "le clergé est plus sensible à Nanterre campus qu'à Nanterre bidonville ${ }^{20}$. " En clair : le «peuple » pourrait n'être aux yeux du clergé que critique Bonnet, qu'une masse à éduquer et éclairer ; à l'inverse, la religion populaire n'est-elle pas plutôt une réalité sui generis à respecter comme dominée ou exclue?

Dans les «Prières secrètes des Français d'aujourd'hui », Bonnet commence par écarter trois façons de caractériser le corpus de prières qu'il a rassemblé et classé. Ce qui s'exprime là n'est pas une sensibilité religieuse "antique ", traditionnelle ou démodée, pas plus que "préchrétienne" au sens des «cultes agraires » primitifs. Il ne s'agit pas non plus de faire passer cela pour l'expression sui generis du génie d'un peuple: "le peuple n'invente pas plus la prière qu'il n'a construit tout seul les cathédrales. N'ajoutons pas un peuple depuis toujours religieux ou spontanément catholique au peuple romantique de Herder, au peuple social de Marx ou au peuple historique de Michelet» (p. 339). Ce serait chercher - et trouver - le " modus operandi » de ces prières dans les productions de genres divers, mêlant hagiographie et théologie. Enfin, il écarte l'idée d'anonymat: pour n'être pas toujours "personnalisées ", ces prières sont « situées » et les vœux qu'elles formulent sont concrets. Bref, le « populaire » n’est ni le primitif, ni un génie primordial, ni l'impersonnel.

Dans un deuxième temps (p. 340-341), recourant à un lexique qu'il éclaire par ses commentaires, il retient quatre traits positifs. D'abord "l'extension ". La diversité est grande dans ces prières et beaucoup peuvent s'y reconnaître dans les mots employés, les lieux, les gestes, et les symboles. Cette extension résulte

18. Ibidem, pp. 395-404 et 455-513.

19. La citation est extraite de l'hebdomadaire Témoignage Chrétien, 20 septembre 1973.

20. S. Bonnet, op. cit., p. 435. 
ensuite d'un jeu « de va-et-vient » entre ce qui est largement vulgarisé et ce qui l'est moins, entre les formulations personnelles et les emprunts sous-jacents, ce qui génère une très grande variété qui est à l'image précisément d'un "peuple ". Le « peuple » en question n'est ni la " classe », ni « la masse », mais une diversité. Le mot peuple se justifie encore, car ces prières sont l'expression d'une solidarité ; elles sont personnelles, mais souvent étendues à d'autres : "la prière sert à se confier à Dieu avec des mots qui vous lient aux voisins". Enfin, l'étude des thèmes prouve selon Serge Bonnet que les préoccupations de tout le monde convergent dans ces expressions.

Bonnet souligne la difficulté de définir le «catholicisme populaire » à partir de ce seul dossier. On peut néanmoins, à partir d'une paraphrase de ce qu'il propose, mettre en évidence une similitude avec l'univers de la culture. Apparaît immédiatement sous sa plume la référence à la norme ou à la légitimité, au sens wébérien du mot réemployé par Bourdieu et Passeron : "On peut essayer, écritil, de situer ce catholicisme populaire par rapport à des normes dogmatiques, liturgiques, canoniques ou éthiques ». Les années où ces pages sont écrites étant riches en débats sur les normes, on comprend qu'il ajoute immédiatement : "Qui peut dresser la liste de ces normes ? L'entreprise est plus difficile à notre époque qu'à beaucoup d'autres ${ }^{21}$. »

Cette situation troublée ou conflictuelle est probablement l'une des sources de l'apparition ou de l'invention du «catholicisme populaire ». Pour s'intéresser $\mathrm{au}$ «populaire » ou au «peuple » - et les allusions de Bonnet à Herder et Michelet l'illustrent bien - il faut une époque en mal de certitudes, comparable à celle des nationalismes naissants. Mutatis mutandis, les effets du Concile Vatican II sont de ce type : remise en cause d'une langue pour en valoriser d'autres, décentralisation et diversification des formes d'expression, déliaison difficile entre religion et culture des élites et liaison difficile avec celle des classes populaires, frictions doctrinales, etc. "De même que la mer, en se repliant sur elle-même, laisse à découvert de vastes étendues de grève, les réformes conciliaires, en s'opérant peut-être trop au niveau des clercs et des militants, ont laissé à l'abandon le vécu populaire ${ }^{22}$. » Cet aveu, déjà évoqué, du chanoine Boulard, un peu plus de vingt ans après la publication de sa carte religieuse de la France rurale, autorise à voir dans les réformes liturgiques des années 1960 et 1970 des effets de la scolarisation de masse et du triomphe des valeurs citadines, des valeurs expressiveséthiques, sur les fonctions rituelles-pratiques du culte.

21. Ibidem., p. 341.

22. F. Boulard, "La religion populaire dans le débat de la pastorale », in Plongeron B. (dir.), La Religion populaire, approches historiques, Paris, Beauchesne, 1976, p. 30-31. 


\section{De Bonnet à Bourdieu et la culture légitime}

En se saisissant de ce vécu abandonné, Bonnet rompt avec l'ethnocentrisme clérical, qui consiste à tout évaluer en fonction de goûts et de normes qui s'imposeraient à tous. Bonnet met entre parenthèse la hiérarchie des façons d'être catholique et donc relativise ce qui est présenté comme l'excellence catholique. Axiome marxien appliqué aux œuvres de culture, et ici aux goûts religieux : les valeurs dominantes sont les valeurs de la classe dominante. On pourrait procéder à une lecture de bien des pages de À hue et à dia à travers cette façon de traiter la culture (et notamment populaire) en sociologie : "Trois variétés de riches se révèlent singulièrement redoutables pour les pauvres. Les riches de la puissance [...] les riches de l'argent [...] les riches du savoir [...]. Les riches de savoir sont les plus insidieux, ils peuvent facilement donner le change sur leur richesse en attaquant les riches de la puissance et de l'argent. Ça ne leur coûte rien contre les autres riches de se poser en avocats des pauvres ${ }^{23}$." On aura reconnu le clergé socio-culturel vitupérant le bourgeois du haut de sa chaire, mais faisant la fine bouche devant des pratiquants peu cultivés et ignorants de l'évolution des goûts catholiques ${ }^{24}$. Ce double jeu assurant sa propre position dans la société... La question de la légitimité culturelle est implicitement posée, quand Bonnet suggère de rapprocher le catholicisme populaire de la «norme » en vigueur dans l'Église. La légitimité culturelle, sous la plume de Bourdieu et Passeron, consiste à transférer au rapport à la culture consacrée, le mécanisme qui, selon Weber, fait qu'une autorité sociale est « reconnue » et ses prescriptions suivies. Devant l'arbitraire ${ }^{25}$ des normes ecclésiastiques, on fait aveu d'ignorance, mais aussi de déférence ou de faiblesse. Et ce, surtout si l'on ne maîtrise pas bien le langage et encore moins les normes pastorales. C'est ce mécanisme qui amena Isambert à parler d'exchristianisation pour désigner les comportements et les demandes jugées par le clergé peu concordantes avec l'esprit d'une pastorale $^{26}$. Le terme pointait le fait que de nouveaux critères d'admission aux sacrements de l'initiation chrétienne ou au mariage, revenaient en pratique à admettre la déchristianisation et à exclure parfois de facto des catholiques peu (ou mal) pratiquants : par exemple en refusant le baptême de leurs enfants à des parents

23. C'est l'incipit du chapitre «Du peuple» dans À hue et à dia, réédité dans S. Bonnet, op. cit., p. 523.

24. Plus loin dans le livre, Bonnet explique avec humour que lorsque dans une prédication il défend les travailleurs immigrés et leur exploitation, il s'attire le soutien d'un public de gauche et se fait traiter de progressiste par les autres; quand il défend la communion solennelle, le sens de la fête, les " autres " sont aux anges; mais dans les deux cas, le clergé lui reproche, soit de n'avoir pas assez parlé des syndicats, soit de confondre la foi et la religion. Cf. S. Bonnet, Défense du catholicisme, op. cit., p. 453.

25. Au sens que ce terme prend dans «l'arbitraire du signe » des linguistes, et que Bourdieu et Passeron appliquent à la culture.

26. F.-A. Isambert, « Le sociologue, le fidèle et le prêtre ", in Mendras H. (dir.), La Sagesse et le désordre, Paris, Gallimard, 1980, p. 223-225. 
non mariés religieusement, ayant abandonné la fréquentation de l'église dès l'enfance, ou n'ayant pas d'intention ferme de donner à leurs enfants une éducation religieuse. Symboliquement, la transformation de la «communion solennelle» en "profession de foi ", ou même sa suppression pure et simple, provoquait des polémiques fréquentes entre clercs ou entre clercs et laïcs. Fallait-il « refouler » des populations peu intégrées à l'Église ? Fallait-il les priver d'une fête organisée autour d'un rite d'initiation, fallait-il de façon dogmatique, restaurer des critères d'implication personnelle pour la réception des sacrements? D'un côté donc, l'affirmation antique sancta sanctis, pour éviter "les sacrements livrés à l'incroyance » ou la « religion contre la foi », et de l'autre, l'argument de « la mèche qui fume encore » ou de l'ostracisme qui frapperait injustement des gens ordinaires.

\section{La critique des armes : nouvelles perspectives sur la légitimité culturelle}

Jean-Louis Fabiani voit dans La Distinction de Bourdieu une œuvre comparable, par la nature et la qualité des questions qu'elle lance, au Suicide de Durkheim et à l'Éthique protestante de Weber ${ }^{27}$. Il pense que, parmi ces questions, celle de la «légitimité culturelle» est celle qui mérite le plus d'être revisitée aujourd'hui. S'il ne voit pas de difficulté particulière à lire « les affinités structurales entre les valeurs des classes privilégiées et les systèmes particuliers voués à la reproduction scolaire de la culture légitime ${ }^{28}$, la chose lui semble plus problématique dans les univers de la production et de la consommation culturelle. Problématique signifie qu'il faut déceler des nuances, des " gradients » dans le phénomène. Bourdieu lui-même signalait en ouverture de La Distinction que la légitimité n'a pas la même force dans tous les arts et, à l'intérieur d'un art, entre toutes les œuvres ${ }^{29}$. Certains domaines donc seraient complètement légitimes et d'autres pas du tout; entendre : c'est seulement dans les premiers, que des normes s'imposent, quel que soit le degré de connaissance dont on dispose.

Il n'a pas fallu trente ans pour le constater, puisqu'en 1994 Olivier Donnat publiait une enquête intitulée: Les Français face à la culture. De l'exclusion à l'éclectisme ${ }^{30}$. Désormais l'homme cultivé, voire snob, est "omnivore " ${ }^{31}$, et celui qui manque de culture peut avoir un accès limité, mais réel aux " grandes œuvres ». Mais la même enquête montre aussi que perdurent les mécanismes de

27. J.-L. Fabiani, «Distinction, légitimité et classe sociale », in Coulangeau P., Duval J. (dir.), op. cit., p. 69-82.

28. Ivi, p.74.

29. P. Bourdieu, op. cit., p 13.

30. Paris, Éditions La Découverte, 1994.

31. Ce terme est proposé en 1996 par R. A Peterson et R. M. Kern, "Changing highbrow taste. From snob to omnivore ", American Sociological Review, vol. 61, n 5, p. 900-907. 
la domination culturelle mis au jour par Bourdieu, comme le montre l'étroite association qui peut être calculée entre origine sociale et préférences culturelles. Certes, on peut parler d'hybridation croissante des univers culturels, phénomène particulièrement sensible dans les générations nées depuis l'après-guerre. Y contribuent entre autres, la consécration de la culture juvénile, la transformation en spectacle de la culture consacrée; au total l'éclectisme culturel permet des combinaisons plus nombreuses et plus variées ; c'est le déclin du pouvoir distinctif de certaines pratiques culturelles comme la lecture. Les effets peuvent en être constatés dans la liturgie catholique où en certains endroits se brouille la distinction entre ce qui est consacré et ce qui l'est moins. Je pense à tel ou tel cantique dont le texte plutôt ésotérique est tiré quasi littéralement de la Bible, sans adaptation, mais mis en musique dans un style que ne renieraient pas les amateurs de bal musette ${ }^{32}$.

Dans le même sens, le livre de Bernard Lahire, La Culture des individus ${ }^{33}$, se présente comme un inventaire critique des thèses de La Distinction et débouche sur des idées proches des précédentes. Pour Lahire, le principe de dissonance (soit la coexistence chez un même individu de goûts culturels puisant dans des formes légitimes et illégitimes) se vérifie dans tous les milieux sociaux. Mais le constat qui vient au début de l'ouvrage n'aide pas beaucoup à cerner la « culture populaire » ${ }^{34}$. Dans la préface à la traduction française du livre de Richard Hoggart, The Uses of Literacy (1957) ${ }^{35}$, Passeron avait livré dès 1970 les bases de ce qu'il développera une dizaine d'années plus tard dans un séminaire conduit avec Claude Grignon. Passeron procède dans ce séminaire à une critique interne des difficultés auxquelles peut mener la théorie de la légitimité culturelle qu'il avait édifiée avec Pierre Bourdieu dans leur livre commun, La Reproduction ${ }^{36}$. Dans sa préface à Hoggart, il avait attiré l'attention sur le fait qu'en discourant sur la culture des autres, les intellectuels peuvent tomber aussi bien dans l'aristocratisme qui idéalise la culture savante, que dans le populisme qui fait le contraire $^{37}$. Le livre de Passeron et Grignon, qui est une critique certes ironique,

32. Il s'agit du cantique "Voici le corps et le sang du Seigneur "; l'auteur confesse dans le quotidien La Croix du 04/12/2015 n'avoir aucune formation musicale.

33. B. Lahire, La culture des individus. Dissonances culturelles et distinction de soi, Paris, Éditions La Découverte, 2004.

34. «Les profils culturels individuels composés d'éléments dissonants sont absolument ou relativement majoritaires dans tous les groupes sociaux (quoique nettement plus probables dans les classes moyennes et supérieures que dans les classes populaires), à tous les niveaux de diplôme (même si beaucoup plus probables chez ceux qui ont obtenu au minimum un baccalauréat que chez les non-diplômés) et dans toutes les classes d'âge (bien que de moins en moins probables quand on va des plus jeunes aux plus âgés) ", Ibidem, p. 13.

35. R. Hoggart, La culture du pauvre. Étude sur le style de vie des classes populaires en Angleterre; "Présentation " par J.-C. Passeron, p. 7-25, Paris, Editions de minuit, 1970.

36. P. Bourdieu, J.-C. Passeron, La reproduction. Éléments pour une théorie du système d'enseignement, Paris, Éditions de Minuit, 1970.

37. Voir J.-C. Passeron, "Présentation", in R. Hoggart, op. cit., p. 8. 
mais interne de la théorie de la légitimité culturelle exposée dans La reproduction, puis radicalisée par Bourdieu seul dans La distinction, n'est pas pour autant, une défense morale de l'autonomie ou de la spécificité des cultures populaires.

On peut interpréter le débat sur le catholicisme populaire du point de vue désigné par Grignon et Passeron comme «légitimiste ». Dans la première partie de cet article, j'ai mis en évidence les indices qui, dans les écrits de Bonnet, en sont l'illustration. L'auteur allait dans ce sens, puisqu'il soulignait le poids d'une légitimité qu'il nommait "cléricale ", mais si proche au fond de la "validité légitime " fondée, selon Weber, sur une "disposition positive, à la légalité de laquelle on croit ${ }^{38}$. Weber poursuit en commentant ce type de légitimité : «La soumission aux ordres est conditionnée [...] par un mélange d'attachement à la tradition et de représentations de la légalité. Dans de très nombreux cas, les acteurs qui se soumettent n'ont pas même conscience qu'il s'agit de coutume, de convention ou de droit ». Le clerc qu'était aussi Bonnet en avait une conscience aigüe et il voyait crument un " ostracisme de classe » dans le procès en indignité fait à des coutumes décalées par rapport aux goûts religieux de certains de ses collègues. Raisonner en termes de légitimité culturelle, c'est en quelque sorte se demander qui a intérêt à définir arbitrairement la norme culturelle, et qui est capable de la prendre non comme une norme opaque à laquelle on se soumet, mais au contraire, comme une sorte de terrain de jeu, une création, ou une émancipation. Bonnet dont la familiarité avec les milieux populaires était grande et pour qui le clergé n'avait guère de secrets ${ }^{39}$, naviguait adroitement entre deux écueils auxquels expose ce que Passeron et Grignon ont désigné et critiqué sous le nom de légitimisme ${ }^{40}$. Pour eux, si l'on plaide pour une autonomie de la culture populaire, on est tenté de tenir un discours populiste idéalisant cette culture $^{41}$; et si l'on traite de cette culture comme une forme de reconnaissance de la culture savante/légitime, sans posséder pour autant la maîtrise de celle-ci, on prend le risque de la dépeindre en termes « misérabilistes ». Grignon et Passeron attirent ainsi l'attention sur le fait que la «connaissance sans reconnaissance » n'est pas une fatalité et ne s'applique pas à tous les domaines. En matière religieuse notamment, et sans aller jusqu'à parler de "résistance des marges ${ }^{42}$.

38. M. Weber, Concepts fondamentaux de sociologie, Textes choisis, traduits de l'allemand et introduits par Jean-Pierre Grossein, Paris, Gallimard, coll. "Tel ", 2016, \$7 " Ordre légitime ", p. 137.

39. On pense à Sociologie politique et religieuse de la Lorraine, Paris, Presses de la Fondation nationale des sciences politiques, 1972, mais aussi aux quatre volumes de L'homme du fer.

40. C. Grignon, J.-C. Passeron, op. cit.

41. On peut courir ce risque avec une expression comme : «La fête est la richesse du pauvre».

42. J.-C. Passeron a précisé sa pensée sur ces questions par exemple dans un entretien donné à la revue Esprit, mars-avril 2002. 


\section{Les classes populaires et la domination culturelle}

Dans le chapitre de La Distinction intitulé «Le choix du nécessaire », Bourdieu parle, à propos des classes populaires, d'un « univers des possibles fermé » et d'un « principe de renoncement à des profits symboliques de toute façon inaccessibles»(p. 441). Face à la culture légitime, les classes populaires sont dans une position de reconnaissance sans connaissance : «l'adaptation à une position dominée implique une forme d'acceptation de la domination. [...] Il serait facile d'énumérer les traits du style de vie des classes dominées qui enferment, à travers le sentiment de l'incompétence, de l'échec ou de l'indignité culturelle, une forme de reconnaissance des valeurs dominantes » (p. 448).

Au cours des années 1980, cette façon de parler des classes populaires ou dominées est critiquée par Grignon et Passeron. Ce geste est perçu comme plus polémique qu'il ne l'était en réalité, mais il permet de faire un bilan critique d'une théorie de la légitimité culturelle. On peut présenter le problème comme celui du degré d'autonomie que possèdent ou manifestent les classes populaires devant les formes officielles ou dominantes de la culture. Or selon Gérard Mauger, une lecture attentive de La distinction montrerait que les classes populaires n'y sont pas présentées comme uniformément et constamment soumises ou hétéronomes. À propos de la "langue populaire ", Bourdieu y précise que " la vision du monde qui s’y exprime représente la limite vers laquelle tendent les membres (masculins) des classes dominées [...] les valeurs de force et de virilité [sont] le seul principe véritable d'une contre-culture ${ }^{43}$... Tout en soulignant qu'il est possible que les effets de la dimension culturelle demeurent actifs, Bourdieu évoque les univers de la politique ou du syndicalisme, comme les lieux de cette autonomie. Pour le reste, dans l'univers de l'art de vivre et sans doute de la religion - cette dernière peu compatible avec la virilité -, la règle, c'est « le choix du nécessaire ", où se mêlent un "matérialisme sceptique ", et un " hédonisme réaliste, le sens de la réjouissance et de la fête " ${ }^{44}$. Se conformer aux rituels religieux serait faire preuve d'une faiblesse plus admissible pour les femmes. Mais ces formes de résistance n'empêchent pas tant s'en faut que s'applique le principe : "Nul ne peut ignorer complètement la loi culturelle " ${ }^{45}$, à commencer par celle de l'école qui est la clé de la position économique ${ }^{46}$. En qualifiant les cultures dominées d' " ambivalentes " 47 vis-à-vis de la culture légitime, Grignon et Passeron ne s'écartaient donc pas tant de Bourdieu. En réalité, l'opposition qui a semblé prévaloir entre les deux auteurs de La Reproduction était sans doute fonction du rapport entretenu par les intellectuels avec la question des

43. P. Bourdieu, op. cit., p. 448.

44. Ibid., 458-459.

45. P. Bourdieu, "Vous avez dit "populaire" ?..." ", Actes de la Recherche en Sciences Sociales, no 56, 1083, p. 103.

46. Id., op. cit., p. 450-452.

47. C. Grignon, J.-C. Passeron, op. cit., p. 21. 
classes populaires. Les discussions sur la façon de définir celles-ci étant, comme le suggérait Bourdieu, "d'abord un enjeu de lutte entre les intellectuels » ${ }^{48}$. Au fond, Robert Pannet ${ }^{49}$ et les prêtres progressistes de la mission ouvrière ont tous une vision intellectualiste de l'ouvrier, mais là où les seconds pensent que celuici trouve - ou pourrait trouver - dans les rites catholiques l'expression de la résistance des classes dominées, le premier veut y lire un sens du sacré spontané. La même vision enchantée de la classe ouvrière produit donc deux positions irréductibles sur le plan pastoral, mais qui reposent l'une et l'autre sur la même sélection de ce qui sort de l'ordinaire, et fait échapper aux traits négatifs de la condition dominée. Trente ans après La Distinction, les transformations des classes populaires que décrit rapidement Mauger ont conduit selon lui à disqualifier ce qui pouvait fonctionner comme principe d'autonomie, notamment les valeurs viriles. On peut penser que ce n'est pas le catholicisme qui bénéficie de ces dispositions plus favorables, mais bien plutôt le protestantisme évangélique, qui imprime son style chaleureux, effusif et exubérant, aux paroisses catholiques des banlieues où se retrouvent classes populaires et notamment les populations immigrées.

\section{Conclusion : improbables équilibres ?}

Le modèle organisé autour de la notion de culture légitime est une clé d'interprétation de la querelle du catholicisme populaire dans la mesure où l'enjeu de cette querelle était bien la définition de l'excellence parmi les manières d'être catholique? La "défense » du catholicisme populaire apparaît dans ce cadre comme une critique adressée à une partie du clergé, au nom d'une conception parfois populiste du sacré et de l'administration des rites. Les classes sociales en général et supérieures en particulier, seraient devenues "omnivores ", au sens où leurs goûts sont hybrides et leurs références composites. Ils consomment des biens culturels de nature très variée. Dans le domaine religieux, Céline Béraud et Philippe Portier ${ }^{50}$ montrent bien dans leur analyse de la place des catholiques dans la "Manif pour tous ", l'étonnante diversité des registres ou " répertoires » de ce mouvement alliant un retour à une théologie morale classique, les méthodes du marketing «communicant » et le recours à l'Église contre la " panique morale ». Le tout place au centre du catholicisme les classes moyennes supérieures, dans un déplacement de perspective plutôt spectaculaire par rapport aux années 1960-1970.

48. P. Bourdieu, article cité, p. 178.

49. R. Pannet, Le catholicisme populaire, Paris, Le Centurion, 1974.

50. C. Béraud, P. Portier, Métamorphoses catholiques. Acteurs, enjeux et mobilisations depuis le mariage pour tous, Paris, Éditions de la Maison des sciences de l'homme, coll. «Interventions ", 2015. 
Un double mouvement est donc à comprendre : l'enjeu est bien toujours de définir l'excellence catholique, et bien des éléments qui sont mobilisés pour ce faire semblent pour souvent sortir du musée où le « clergé socio-culturel » voulait les enfermer. D'autre part, la scène est toujours celle d'une stratégie de distinction. Dans sa présentation des textes de Serge Bonnet, Yann Raison du Cleuziou note avec perspicacité que là où un clergé progressiste manipulait les bonnes et mauvaises manières d'être catholique, un clergé néo-classique qui ne craint pas d'affirmer son identité, critique ou rejette, aujourd'hui, ceux des laïcs qui «font des complexes ", ou sont tièdes, se posent trop de questions et ne manifestent pas un enthousiasme de tous les instants pour la foi catholique et pour le Magistère ${ }^{51}$. Les contenus changent, l'éthos des acteurs aussi, mais le processus de création et d'imposition d'une légitimité demeure constant. En quarante ans, ceux qui occupaient le haut du pavé sont maintenant dans la position qu'occupaient les «catholiques populaires ».

Jacques Lagroye, dans La vérité dans l'Église catholique ${ }^{52}$, apporte une lumière utile au fonctionnement de la légitimité parmi les catholiques; il souligne comment l'institution est un dispositif régulant des interactions et limitant leurs aléas; dans l'institution catholique, le monopole exercé par le clergé sur les sacrements n'exclut pas divisions, conflits et diversité, mais les limite fortement. Cette limitation s'exerce de deux façons. Bien évidemment par le monopole de l'administration des rites; la pratique largement répandue de la prise en charge des obsèques par des laïcs n'existe que sous mandat donné par l'évêque et dans le respect des formes. La deuxième façon d'éviter les conflits est de concéder des adaptations. L'exemple des obsèques l'illustre également : les membres de la famille du défunt participent au rituel et peuvent intervenir pour évoquer la mémoire du disparu, lire des poèmes et choisir des chants et des musiques. Plus largement Lagroye emprunte à Michel Foucault une distinction entre deux régimes de vérité en concurrence. Un régime « de certitude » et un régime "de témoignage ». Celuici consiste à faire droit à l'expérience des fidèles, à favoriser leur implication et leur expression personnelles et à concéder les adaptations rituelles nécessaires à cet effet. Celui-là consisterait en une faible implication de ceux, clercs ou laïcs qui accompagnent les demandeurs de rites, en un discours plus enclin à dire la norme qu'à chercher le sens.

Partant de là, le débat sur le catholicisme populaire est une des figures que prend le conflit multiforme entre les différentes façons dont les clercs proposent les rites et dont les laïcs les demandent et les reçoivent. Les formes de ce conflit et d'abord son existence, tiennent à l'attractivité de l'Église, aux propriétés sociales des clercs et à celles des laïcs. Par rapport à ce début de XXI ${ }^{\mathrm{e}}$ siècle, le clergé est aujourd'hui moins divisé que dans les années 1970, plus enclin à un "régime

51. Y. Raison du Cleuziou, "Présentation", in S. Bonnet, op. cit., p. 47.

52. J. Lagroye, La vérité dans l'Église catholique. Contestations et restauration d'un régime d'autorité, Paris, Belin, 2006. 
de vérité " plutôt vertical, de certitude, sans que l'autre modalité ait disparu, l'information méthodiquement collectée sur ces questions est rare ${ }^{53}$. L'acceptation même tacite de ce rapport est bien une question de légitimité, car, comme le souligne Lagroye, ce n'est pas la vigueur des raisonnements tenus par le clergé ou les connaissances de celui-ci qui entraînent l'assentiment ; compte tenu de la tradition dans laquelle on s'inscrit, "les discours émis par les clercs [...] sont tenus pour des interprétations sûres et seules autorisées de la vérité révélée " ${ }^{54}$. Le régime du témoignage, lui, permet de considérer comme vrai ce qui est médiatisé dans une relation personnelle. Il a connu une sorte d'officialisation avec la lettre aux catholiques de France conçue par les évêques sous le titre "Proposer la foi dans la société actuelle».

Ces deux régimes de vérité peuvent très bien être pratiqués par les mêmes individus selon les circonstances et les interlocuteurs. Et surtout, tout est fait pour que la dualité soit déniée et que le régime de certitude apparaisse même comme un impératif. Lagroye n'est pas loin de penser que le mouvement charismatique habille ce régime d'une jubilation dont la chaleur dispense de s'interroger sur les lumières qu'elle dispense. Mais nous revoilà dans le débat. Concluant sa présentation du livre de F.-A. Isambert, Le sens du sacré et le métier de sociologue, Paul Ladrière suggérait, bien après le plus vif du débat, qu'il était possible, à la manière dont le fait Isambert, de prendre à nouveaux frais des questions fondamentales que le débat des clercs a fait entrevoir :

La tension entre l'ordre hiératique et l'ordre communionnel occupe l'essentiel du champ religieux, mais elle s'inscrit entre deux pôles. L'un peut être dit cosmique. Il fait du sacré originel, dont le paganisme serait encore porteur sous la figure actuelle de la religion populaire, l'assise nécessaire du christianisme. L'autre pôle peut être dit éthique. Il récuse le sacré et fait de l'exigence éthique le seul espace à l'intérieur duquel le christianisme devient possible ${ }^{55}$.

Cette analyse est doublement intéressante ou significative. Elle prend le problème à sa racine, mais ce faisant, elle côtoie le risque de le trancher souverainement. Sociologie de la culture et sociologie de la religion ne peuvent éviter de placer leurs doigts dans l'engrenage des présupposés ou des choix moraux et philosophiques ${ }^{56}$.

André ROUSSEAU

Centre de Recherche Bretonne et Celtique

Université Bretagne Occidentale rousseauandre18@gmail.com

53. Le travail de C. Béraud et P. Portier fait exception et justifie l'hypothèse avancée ici.

54. J. Lagroye, op. cit., p. 1.

55. P. Ladrière, "Le sens du sacré et le métier de sociologue », Archives de sciences sociales des religions, 1984, 57/1 (janvier-mars), p. 136.

56. Ce que souligne J.-C. Chamborédon dans sa présentation critique du livre de Grignon et Passeron, "La sociologie comme théorie des cultures de classe ", Revue Européenne des Sciences Sociales, XXXIV, 1996, n 103, 109-117. 